\title{
Resting energy expenditure in Duchenne patients using home mechanical ventilation
}

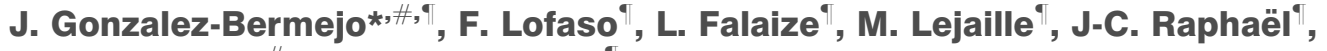 \\ T. Similowski* ${ }^{*}$ and J-C. Melchior"
}

\begin{abstract}
Nutritional status is both important and difficult to assess in patients with Duchenne muscular dystrophy (DMD), particularly in those requiring mechanical ventilation (MV). The current authors evaluated body composition (bio-impedancemetry), resting energy expenditure (REE; indirect calorimetry) and energy intake in 20 adult patients with DMD using home MV (nocturnal: $n=13$; continuous: $n=7$ ) and 12 age-matched healthy controls.

The patients were smaller in height than the controls and had a lower body weight. Most of the reduction in body mass index was accounted for by a reduction in fat free mass (FFM). REE (kJ) was significantly reduced in the patients $\left(4559 \pm 853 \mathrm{~kJ} \cdot 24 \mathrm{~h}^{-1}\right.$ versus $\left.7407 \pm 1312 \mathrm{~kJ} \cdot 24 \mathrm{~h}^{-1}\right)$, but the difference disappeared after correction for FFM.

REE and FFM were correlated in both the controls and patients, but less strongly in the latter, the lower strength of the association being due to the patients using continuous MV (REE and FFM uncorrelated). The food intake of the patients was $1.2 \pm 0.4$ greater than their REE.

This study shows that patients with advanced forms of Duchenne muscular dystrophy have balanced energy intakes and resting energy expenditure.
\end{abstract}

KEYWORDS: Chronic respiratory insufficiency, Duchenne muscular dystrophy, home mechanical ventilation, nutritional status, resting energy expenditure

D uchenne muscular dystrophy (DMD) is the most frequent congenital muscle dystrophy, with a frequency of one per 3,500 male births. The deficient expression of the dystrophin gene is held responsible for a dramatic loss in muscle mass. Around $10 \mathrm{yrs}$ of age young males with DMD have a muscle mass $\sim 75 \%$ lower than normally expected [1-3], and generally become wheelchair bound. Respiratory failure is the main cause of death, but the widespread use of mechanical ventilation (MV) has dramatically prolonged the lifespan of these patients. In fact it is now not exceptional to see DMD patients live through their third or even fourth decade $[4,5]$, whereas historically they died aged $\sim 19$ yrs [4].

As is the case for all neuromuscular diseases, nutritional status is an important issue in patients with DMD. Indeed, malnutrition can aggravate muscle wasting [6]. It increases the risk of complications, such as pressure sores, and reduces the defence against infections [7, 8]. Several mechanisms can impair nutrition in DMD patients at an advanced stage of the disease. First, their food intake can be compromised by major feeding difficulties due to locomotor disability or swallowing difficulties due to the weakness of oropharyngeal muscles [9]. Secondly, certain intercurrent events, such as infections, are known to increase muscle catabolism [10]. However, overfeeding to improve muscle protein synthesis [11] is ineffective [12] and can cause obesity in children with DMD [13]. In severely affected patients, still breathing spontaneously, it carries the risk of acute hypercapnia due to an increased carbon dioxide production that cannot be matched by a corresponding increase in alveolar ventilation [14, 15] unless MV is provided.

In spite of their clinical relevance, data describing the metabolic requirements and nutritional intake of DMD patients are relatively scarce, and virtually nonexistent for those patients who have reached the stage of MV. This may be, in part, because nutritional assessment of DMD patients is not straightforward; for example, the body mass index (BMI) is of little help from a nutritional point of view because of the loss of muscle mass due to the primary pathology of DMD [16]. Whether MV alters metabolic requirements and necessitates specific nutritional adjustments is not precisely known. For these reasons, the current authors evaluated, as precisely as possible, the nutritional status, body composition, energy expenditure and energy intake of adult
AFFILIATIONS

* Service de pneumologie et de réanimation, GH Pitié-Salpêtrière, Assistance Publique - Hôpitaux de Paris,

\#UPRES EA2397, Université Paris VI Pierre et Marie Curie, Paris, and

- Services de Réanimation Médicale, Physiologie - Explorations Fonctionnelles, Maladies Infectieuses et Tropicales-Nutrition Clinique, et Centre d'Innovation Technologique Hôpital Raymond Poincaré AP-HP, Garches, France.

\section{CORRESPONDENCE}

J. Gonzalez-Bermejo

Service de Pneumologie et de

Réanimation

Groupe Hospitalier Pitié-Salpêtrière Assistance Publique-Hôpitaux de Paris

47-83

Bd de I'Hôpital

75651 Paris Cedex 13

France

Fax: 33142176708

E-mail: jesus.gonzalez@psl.

ap-hop-paris.fr

Received:

March 132004

Accepted after revision:

December 062004

SUPPORT STATEMENT

This study was supported in part by Association pour le Développement et l'Organisation de la Recherche en Pneumologie, Paris, France.

European Respiratory Journal

Print ISSN 0903-1936

Online ISSN 1399-3003 
DMD patients using home MV. The present study compares patients using nocturnal-only ventilatory assistance with patients using continuous ventilation, to gain an insight into the contribution of ventilatory muscle to energy expenditure during DMD.

\section{MATERIALS AND METHODS Study subjects}

In total, 20 adult patients were studied (table 1), on a consecutive basis, on the occasion of a routine follow-up. The diagnosis of DMD was based on clinical, familial, electromyographic, and genetic data. Of these, 13 patients received nocturnal-only MV (noninvasive in nine cases and via a tracheostomy in four cases). The remaining seven patients were continuously dependent on their ventilator (tracheostomy in all of these cases). All patients used volumecontrolled MV as provided by an Eole $3^{\mathrm{TM}}$ ventilator (Saime, Savigny-le-Temple, France), either noninvasively or through a tracheotomy. All patients received nutritional intake orally and none had a gastrostomy. No build-up drinks or food supplements were used. They all reported eating slowly and with difficulty, but stated that these inconveniencies were largely compensated by the pleasure to eat normal meals with cooked dishes.

Exclusion criteria included a recent episode of acute infection ( $<6$ weeks), an unstable cardiac condition, active gastrointestinal

\begin{tabular}{|c|c|c|c|}
\hline & Controls & DMD patients & p-value \\
\hline Subjects n & 12 & 20 & \\
\hline Age yrs & $28 \pm 7$ & $25 \pm 4$ & 0.08 \\
\hline Body weight kg & $72 \pm 16$ & $48 \pm 19$ & 0.002 \\
\hline Height $\mathbf{c m}$ & $172 \pm 9$ & $165 \pm 8$ & 0.03 \\
\hline Body mass index & $24 \pm 5$ & $17 \pm 6$ & 0.003 \\
\hline Fat free mass weight $\mathrm{kg}$ & $58 \pm 10$ & $37 \pm 10$ & $<0.0001$ \\
\hline $\begin{array}{l}\text { Measured resting energy } \\
\text { expenditure }\end{array}$ & & & $<0.0001$ \\
\hline $\mathrm{kJ} \cdot 24 \mathrm{~h}^{-1}$ & $7407 \pm 1312$ & $4559 \pm 853$ & \\
\hline $\mathrm{kCal} \cdot 24 \mathrm{~h}^{-1}$ & $1763 \pm 312$ & $1085 \pm 203$ & \\
\hline Respiratory quotient & $0.88 \pm 0.06$ & $0.89 \pm 0.1$ & 0.7 \\
\hline Food intake & & & NA \\
\hline$k J \cdot 24 h^{-1}$ & NA & $5536 \pm 1432$ & \\
\hline $\mathrm{kCal} \cdot 24 \mathrm{~h}^{-1}$ & NA & $1317 \pm 340$ & \\
\hline Protein intake $\mathrm{g} \cdot 24 \mathrm{~h}^{-1}$ & NA & $76 \pm 27$ & NA \\
\hline $\begin{array}{l}\text { Vital capacity } \mathrm{mL} \text { (\% of } \\
\text { pred) }\end{array}$ & NA & $678 \pm 399(13 \pm 7)^{\#}$ & NA \\
\hline $\mathrm{Pa}, \mathrm{CO}_{2} \mathrm{mmHg}$ & NA & $42 \pm 8$ & NA \\
\hline $\mathrm{CO}_{2}$ total $\mathrm{mmol} \cdot \mathrm{L}^{-1}$ & NA & $26.1 \pm 3.3$ & NA \\
\hline $\mathrm{Pa}, \mathrm{O}_{2} \mathrm{mmHg}$ & NA & $96 \pm 11$ & NA \\
\hline pH & NA & $7.40 \pm 0.03$ & NA \\
\hline
\end{tabular}

Data presented as mean $\pm \mathrm{SD}$. DMD: Duchenne muscular dystrophy; kJ: kilo Joules; $\mathrm{kCal}$ : kilo Calorie; $\mathrm{Pa}_{1} \mathrm{CO}_{2}$ : carbon dioxide arterial tension; $\mathrm{Pa}_{1} \mathrm{O}_{2}$ : arterial oxygen tension; NA: not available. ${ }^{\#}$ : predicted values from the European Respiratory Society equations. $\mathrm{kPa}=\mathrm{mmHg} \times 0.133$. abnormalities, recent surgery, diabetes mellitus and thyroid disorders. No patients were taking corticosteroids.

The protocol was approved by the ethics committee of the Société de Reanimation de Langue Française, Paris, France.

\section{Controls}

Data obtained from 12 healthy subjects, recruited from the authors' own laboratory, served as controls for the validation of the measurement techniques.

\section{Methods}

The serum concentrations of albumin, pre-albumin and Creactive protein were measured from venous blood samples.

The fat free mass (FFM) and the fat mass were determined using dual frequency $(5 \mathrm{kHz}$ and $100 \mathrm{kHz})$ bio-electricalimpedance analysis, (Analycor®; Eugédia-Spengler, Chambly, France) performed with the subjects in the supine position [16].

Resting energy expenditure (REE) was calculated from the results of indirect calorimetry and urinary nitrogen production, according to BEN-PORAT et al. [17]. Oxygen consumption $\left(V^{\prime} \mathrm{O}_{2}\right)$ and carbon dioxide production were measured using an open-circuit metabolic cart (Sensormedics Horizon System; Sensormedics, Anaheim, CA, USA) and a ventilated canopy [18]. The subjects were studied in the supine position, after becoming accustomed to the equipment, in a quiet room at $24^{\circ} \mathrm{C}$. The measurements were performed between 08:0009:00 h, after an overnight fast of $\geqslant 12 \mathrm{~h}$. In the nocturnal-only ventilation patients, $\mathrm{MV}$ was interrupted $\geqslant 12 \mathrm{~h}$ before the measurements were made.

To estimate calorific intake, the patients were instructed to record precisely their food intake over 3 days during the week immediately preceding the study. The records were reviewed in detail with the assistance of food models [19]. The daily energy and protein intakes were calculated, expressed in $\mathrm{kJ} \cdot 24 \mathrm{~h}^{-1}$, and averaged over the 3 days.

\section{Predicted values}

The measured resting energy expenditure (mREE) was compared to the theoretical energy expenditure (tREE) as described by the HARRIS and BENEDICT [20] equation. The use of body weight in the Harris and Benedict equation is not appropriate for DMD patients due to their pathological changes in body composition. Therefore, FFM adjusted resting energy expenditure (fREE) was computed using the relationship observed between REE and FFM in the control subjects $[18,21,22]$.

\section{Analysis}

All the variables are described as mean \pm SD. The relationship between REE and FM was assessed by Pearson correlation coefficients, after verifying that these variables followed a Gaussian distribution. Differences between correlation coefficients were tested for significance using the Fischer r-to-z transformation. Within group comparisons of observed versus predicted values were made using a paired t-test. Comparisons between the groups were made using an unpaired t-test. Statistical significance of differences was assumed when the risk of type I error was $<5 \%$. 


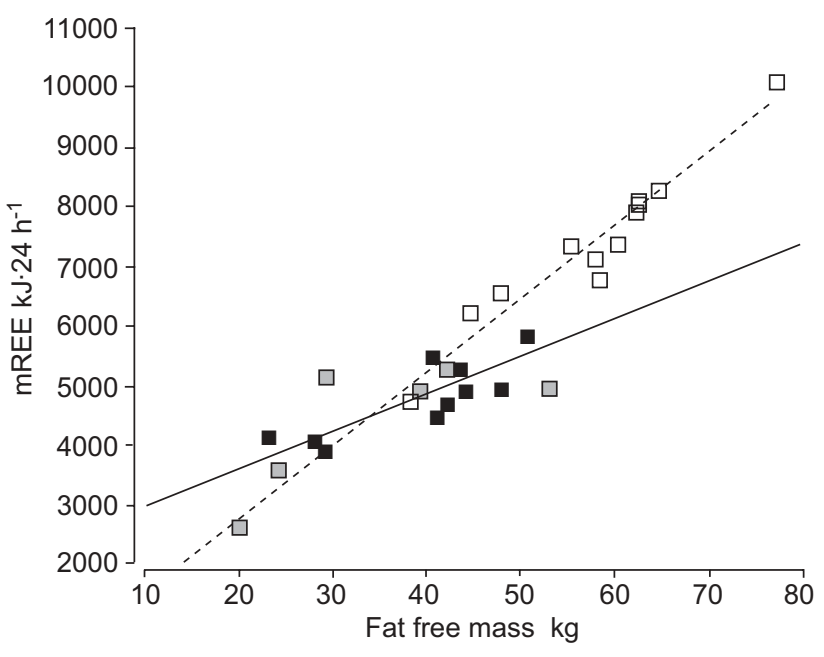

FIGURE 1. Relationship between measured resting energy expenditure (mREE) and fat free mass (FFM) in the control subjects ( $\square$ ) and the Duchenne patients studied during spontaneous breathing ( $\mathbf{\square})$ or using mechanical ventilation ( $\square$ ). The curvilinear lines indicate the $95 \%$ confidence interval of the correlation between $\mathrm{MREE}$ and FFM in the two groups.

\section{RESULTS}

\section{Body weight, body composition and serum proteins}

Compared with the 12 age-matched controls, DMD patients were smaller in height and had a lower body weight. The reduction in weight was disproportionately greater than the reduction in size, hence, a significantly smaller BMI. Most of the reduction in BMI was accounted for by a reduction in FFM (table 1). All serum albumin values except one were $>35 \mathrm{~g} \cdot \mathrm{L}^{-1}$. All serum pre-albumin values were $>0.2 \mathrm{~g} \cdot \mathrm{L}^{-1}$, except in three cases, including one with low albumin. All serum C-reactive protein values were $<5 \mathrm{mg} \cdot \mathrm{L}^{-1}$.

\section{Resting energy expenditure}

In the control subjects, mREE slightly but significantly exceeded tREE, as previously described [23]. mREE was strongly correlated with FFM $(\mathrm{R}=0.97 ; 95 \%$ confidence interval (CI) 0.89-0.99; $\mathrm{p}<0.0001$; fig. 1).

In DMD patients as a whole, mREE was significantly lower than in controls $\left(4559 \pm 853 \mathrm{~kJ} \cdot 24 \mathrm{~h}^{-1}\right.$ versus $7407 \pm 1312 \mathrm{~kJ} \cdot 24 \mathrm{~h}^{-1}$, respectively; $\mathrm{p}<0.0001$ ). It was also markedly lower than $\mathrm{tREE}$, by $22 \%$ on average $\left(4559 \pm 853 \mathrm{~kJ} \cdot 24 \mathrm{~h}^{-1}\right.$ versus $5766 \pm 1187$ $\mathrm{kJ} \cdot 24 \mathrm{~h}^{-1}$, respectively; $\mathrm{p}<0.0001$ ). Conversely, mREE and fREE were not significantly different $\left(4559 \pm 853 \mathrm{~kJ} \cdot 24 \mathrm{~h}^{-1}\right.$ versus $4826 \pm 1274 \mathrm{~kJ} \cdot 24 \mathrm{~h}^{-1}$, respectively; $\mathrm{p}=0.4$; table 2 ). As in the controls, mREE and FFM were correlated $(\mathrm{R}=0.79 ; 95 \% \mathrm{CI} 0.50$ $0.93 ; \mathrm{p}<0.0001)$, but the strength of this association was significantly lower than in the controls ( $\mathrm{R}$ difference $0.17 ; 95 \%$ CI $0.10-0.94 ; \mathrm{p}=0.0264)$. When the continuous ventilatory support patients were removed from the analysis, the correlation between $\mathrm{mREE}$ and FFM ( $\mathrm{R}=0.830 ; 95 \%$ CI $0.420-0.959)$ was not significantly different from the controls.

TABLE 2 Individual anthropometric and energetic data in the 20 Duchenne patients

\begin{tabular}{|c|c|c|c|c|c|c|c|c|}
\hline $\begin{array}{l}\text { Patient } \\
\text { No. }\end{array}$ & $\begin{array}{l}\text { Age } \\
\text { yrs }\end{array}$ & $\begin{array}{c}\text { Height } \\
\text { cm }\end{array}$ & $\begin{array}{c}\text { Weight } \\
\text { kg }\end{array}$ & BMI & $\begin{array}{c}\text { mREE } \\
k J \cdot 24 h^{-1}\end{array}$ & $\begin{array}{c}\text { tREE } \\
k J \cdot 24 h^{-1}\end{array}$ & $\begin{array}{c}\text { fREE } \\
k J \cdot 24 h^{-1}\end{array}$ & $\begin{array}{c}\text { Energy intake } \\
\mathrm{kJ} \cdot 24 \mathrm{~h}^{-1}\end{array}$ \\
\hline 1 & 22 & 168 & 56 & 20 & 5299 & 6395 & 5394 & 4947 \\
\hline 2 & 22 & 164 & 62 & 23 & 4897 & 6659 & ND & 5640 \\
\hline 3 & 24 & 163 & 46 & 17 & 5487 & 5684 & 5234 & 5010 \\
\hline 4 & 29 & 160 & 25 & 10 & 2649 & 4248 & 2640 & 2176 \\
\hline 5 & 20 & 160 & 30 & 12 & 3947 & 4788 & 3797 & 7927 \\
\hline 6 & 22 & 145 & 26 & 12 & 3034 & 4190 & ND & 4186 \\
\hline 7 & 21 & 170 & 29 & 10 & 4152 & 4834 & 3077 & 8371 \\
\hline 8 & 26 & 160 & 34 & 13 & 5157 & 4818 & 3838 & 7241 \\
\hline 9 & 34 & 165 & 44 & 16 & 4504 & 5303 & 5296 & 4880 \\
\hline 10 & 22 & 160 & 63 & 25 & 5286 & 6642 & 5592 & 5617 \\
\hline 11 & 26 & 165 & 25 & 9 & 3562 & 4416 & ND & 4332 \\
\hline 12 & 21 & 162 & 39 & 15 & 4926 & 5634 & 5031 & 4926 \\
\hline 13 & 22 & 181 & 63 & 19 & 4956 & 6383 & 6137 & 5521 \\
\hline 14 & 26 & 164 & 60 & 22 & 4700 & 6429 & 5430 & 7588 \\
\hline 15 & 28 & 180 & 62 & 19 & 4951 & 6822 & 5651 & 5479 \\
\hline 16 & 27 & 162 & 32 & 12 & 3587 & 4725 & 3217 & 5458 \\
\hline 17 & 28 & 170 & 78 & 27 & 5161 & 7253 & ND & 5801 \\
\hline 18 & 24 & 175 & 75 & 24 & 4997 & 7580 & 6738 & 5023 \\
\hline 19 & 21 & 170 & 83 & 29 & 5860 & 8024 & 6488 & 4391 \\
\hline 20 & 33 & 163 & 30 & 11 & 4072 & 4495 & 3660 & 6199 \\
\hline Mean \pm SD & $25 \pm 4$ & $165 \pm 8$ & $48 \pm 19$ & $17 \pm 6$ & $4559 \pm 853$ & $5766 \pm 1187^{\#}$ & $4826 \pm 1274$ & $5536 \pm 1432$ \\
\hline
\end{tabular}

BMI: body mass index; mREE: measured resting energy expenditure (REE); tREE: theoretical REE with Harris and Benedict equation; fREE: fat free mass adjusted REE; kJ: kilo joules. \#: difference between tREE and mREE, $p<0.0001$ when compared with mREE; ": difference between energy intake and mREE, $p<0.008$ when compared with $\mathrm{MREE}$. 
In the seven patients continuously dependent on MV, mREE was significantly lower than in the 13 patients using nocturnalonly ventilation $(4000 \pm 960 \mathrm{~kJ}$ versus $4900 \pm 650$, respectively; $\mathrm{p}=0.0200$ ), with the difference averaging $19 \%$. Body weight, BMI and FFM did not differ significantly between the two patient subgroups. In the continuously ventilated patients, the correlation between $\mathrm{mREE}$ and FFM did not reach significance $(\mathrm{R}=0.705 ; 95 \% \mathrm{CI}-0.249-0.965 ; \mathrm{p}=0.1286)$, but the number of observations was small.

\section{Energy intake}

On average, the energy intake of DMD patients was $1.2 \pm 0.4$ greater than their mREE $\left(5536 \pm 1432 \mathrm{~kJ} \cdot 24 \mathrm{~h}^{-1}\right.$ versus $4559 \pm$ $853 \mathrm{~kJ} \cdot 24 \mathrm{~h}^{-1}$, respectively; $\mathrm{p}=0.008$; table 2 ). This was true in nocturnal-only ventilated patients, as well as in continuously ventilated patients.

Only four patients had an energy intake lower than their mREE. In two cases, the difference did not exceed $1 \%$. One patient was on a diet due to obesity $(B M I=29)$ and one patient had an energy intake $9 \%$ lower than his mREE. This was the only patient with a low albumin $\left(30.8 \mathrm{~g} \cdot \mathrm{L}^{-1}\right.$; lower limit of the normal range in the laboratory: $\left.41 \mathrm{~g} \cdot \mathrm{L}^{-1}\right)$ and a low prealbumin $\left(0,181 \mathrm{~g} \cdot \mathrm{L}^{-1}\right.$; lower limit of the normal range in the laboratory: $\left.0.203 \mathrm{~g} \cdot \mathrm{L}^{-1}\right)$.

\section{DISCUSSION}

The present study shows that patients with advanced forms of DMD have balanced energy intakes and REE, and, hence, are not likely to suffer from significant malnutrition. The magnitude of the difference in REE between the patients using continuous MV and the patients using nocturnal-only ventilation suggests there is more to this difference than the contribution of ventilatory muscles, in this setting.

\section{Methodological considerations}

Height can underestimate arm span in patients suffering neuromuscular diseases, due to scoliosis. All patients in the current study had undergone surgical correction of scoliosis (on average when aged 11-13 yrs, and before spinal curvature had reached $25^{\circ}$ ). Patients height was determined with a tape measure during stretching, in order to adjust for scoliosis. Therefore, the authors are confident that the BMIs provided were not an over overestimation. The most common way to predict REE in clinical practice is to apply the Harris and Benedict equations [20], which take into account sex, age, height and body mass. The present results (averaging a $22 \%$ difference between measured values and Harris and Benedict predicted values) corroborate observations made in other settings [21], and confirm that this approach is erroneous in the presence of a reduced muscle mass. Conversely, predicting REE from its relationship to FFM established in controls appears to be as valid in patients with DMD as in other types of patients [18, 21, 22]. This study assessed FFM from bioelectrical impedancemetry. This has not been formally validated in patients with neuromuscular diseases and could have specific drawbacks in this setting. However, compared with other techniques, such as dual-energy X-ray absorpiometry [2], total-body potassium determination [24], whole-body densitometry [2], magnetic resonance imaging or deuterium dilution $[21,25]$, bio-electrical impedance analysis is the only practical method in ventilator-dependent patients who have reached a stage where full assistance is required to move from the bed or wheelchair. Furthermore, some of the other techniques cannot be performed for technical reasons in these patients (for example, all study patients had undergone surgical correction of scoliosis with Harrington or Luque rods making magnetic resonance imaging impossible). Although the patients who were not continuously ventilator-dependent could have been assessed by some of the above techniques, the choice of bioelectrical impedance allowed the authors to assess FFM homogeneously in the two patient populations. There is a clear need for a validation of bio-electrical impendance analysis of FFM for neuromuscular patients.

\section{Energy expenditure and neuromuscular diseases}

The medical literature is scarce on this topic. In adult patients with various types of neuromuscular disease, including some DMD patients, MCCRORY et al. [26] found a preserved REE but a reduced total daily energy expenditure. In patients with myotonic dystrophy, JOSEFOWICZ et al. [24] reported a reduction in REE expressed as a function of body surface area, but an augmentation when expressed as a function of FFM. In children with DMD, compared to age-matched controls, HANKARD et al. [27] found a decreased REE. This decrease became nonsignificant after correction for FFM, suggesting that muscle attrition was a major factor in the REE. Similarly, ZANARDI et al. [28] failed to demonstrate a low REE in a small group of children with DMD. This does not seem to hold true in the patients presented. Indeed, a markedly reduced energy expenditure was found, which was directly proportional to the loss in FFM, as indicated by the lack of significant difference between the measured values of REE and the values predicted by FFM adjustment procedure. The difference between the studies of HANKARD et al. [27], ZANARDI et al. [28] and the present study could be explained by the radically different nature of the populations studied. HANKARD et al. [27] studied children with little reduction in BMI and who did not require ventilatory assistance. This was also the case for ZANARDI et al. [28]. Patients in the current study, however, were adults, had a dramatically reduced muscle mass and had patent chronic respiratory insufficiency. In the studies of MCCRORY et al. [26], HANKARD et al. [27], and ZANARDI et al. [28], the patients were not mechanically ventilated and had a relatively preserved FFM. In this regard, it is important to keep in mind the data provided by ZURLO et al. [29], showing that skeletal muscle can account for up to $20 \%$ of REE, and the data of KAYSER [30] showing that skeletal muscle is responsible for $25 \%$ of $V^{\prime} \mathrm{O}_{2}$ of the body.

\section{Insights into the impact of ventilatory muscle activity on resting energy expenditure}

In the 13 patients studied while breathing spontaneously, the strength of the association between REE and FFM was not significantly lower than in the controls. Conversely, in the seven patients who were ventilator dependent and, thus, were studied in the absence of ventilatory muscle activity, there was no correlation between REE and FFM. Caution is called for by the small number of patients in this category, suggesting that it is possible to observe a quasi-suppression of the contribution of skeletal muscle to REE at an extreme stage of the disease when the viscera alone constitute the FFM and, thus, become the main factors influencing REE. Although the absence of 
ventilatory muscle activity during the metabolic measurements is one of the main differences between the two groups of patients, it is unlikely that this suffices to fully explain the observed gap in REE, even in the presence of, for example, a micro-atelectasis-related increase in the work of breathing. Indeed, the average difference in REE between the two categories of patients with DMD amounted to $19 \%$, a figure which is much greater than the energy expenditure of the human respiratory muscles at rest, namely $1-2 \%$ of the total REE [31]. Nevertheless, it seems reasonable to postulate that in patients who switch from assisted to spontaneous breathing, important fluctuations in REE can occur. Of note, the present results suggest that no specific nutritional measures are needed when patients with DMD go from nocturnal-only to continuous ventilatory support, if their condition is otherwise stable (see below).

\section{Practical implications}

This study provides a picture, although not comprehensive, of the nutritional status of adult patients with DMD having reached the stage of the disease when ventilatory support is needed. It appears that, in a stable clinical condition, nutritional intake and energy expenditure are reduced proportionately and, hence, grossly balanced. The mechanisms of this reduction are unclear, but may reflect a homeostatic adaptation to the reduction in muscle mass (of note, patients had been given general nutritional recommendations, e.g. how to balance the daily intake of the main nutrients, but were not following any kind of specific nutritional programme). Therefore, from a practical point of view the authors believe that patients with DMD should receive standard nutritional education and be told to eat ad libitum in order to satisfy perceived hunger and their weight should be precisely monitored. Any significant increase or decrease in weight, in the absence of obvious factors, such as an infectious state or sodium retention, should prompt a measure of the FFM and the energy expenditure in order to guide nutritional adaptations. In future studies, the value of fat mass as a nutritional marker in DMD should be specifically evaluated, due to its independence from the disease-related muscle loss.

Of note, it is difficult, if at all possible, to put the results from the present study and the above proposition into the perspective of the nutritional recommandations derived from the weight percentile chart proposed by GRIFFITHS and EDWARDS [1, 32-35]. Indeed, these data pertain to children only, whereas the youngest patient in this study was aged 21 yrs.

Alternatively, the hypothesis of a primary reduction in food intake (whatever its mechanism) as the source of an accelerated loss in muscle mass, and in turn of the REE, must be considered.

\section{Perspectives}

To better understand the nutritional processes at play in patients with Duchenne muscular dystrophy longitudinal data on energy expenditure and calorie intake are needed. Gaining a better knowledge of the changes in energy expenditure and food intake that are associated with infections, and with the course of the Duchenne muscular dystrophy-related cardiomyopathy, would be particularly important. This knowledge would help clinicians to better monitor patients with
Duchenne muscular dystrophy to precisely adapt energy intake to energy expenditure in situations such as surgery, intercurrent infections, cardiac insufficiency or respiratory failure.

\section{REFERENCES}

1 Griffiths RD, Edwards RH. A new chart for weight control in Duchenne muscular dystrophy. Arch Dis Child 1988; 63: 1256-1258.

2 Kanda F, Fujii Y, Takahashi K, Fujita T. Dual-energy X-ray absorptiometry in neuromuscular diseases. Muscle Nerve 1994; 17: 431-435.

3 Willig TN, Carlier L, Legrand M, Riviere H, Navarro J. Nutritional assessment in Duchenne muscular dystrophy. Dev Med Child Neurol 1993; 35: 1074-1082.

4 Eagle M, Baudouin SV, Chandler C, Giddings DR, Bullock R, Bushby K. Survival in Duchenne muscular dystrophy: improvements in life expectancy since 1967 and the impact of home nocturnal ventilation. Neuromuscul Disord 2002; 12: 926-929.

5 Gomez-Merino E, Bach JR. Duchenne muscular dystrophy: prolongation of life by noninvasive ventilation and mechanically assisted coughing. Am J Phys Med Rehabil 2002; 81: 411-415.

6 McLoughlin DM, Wassif WS, Morton J, Spargo E, Peters TJ, Russell GF. Metabolic abnormalities associated with skeletal myopathy in severe anorexia nervosa. Nutrition 2000; 16: 192-196.

7 McMurray DN, Watson RR, Reyes MA. Effect of renutrition on humoral and cell-mediated immunity in severely malnourished children. Am J Clin Nutr 1981; 34: 2117-2126.

8 Keusch GT. The history of nutrition: malnutrition, infection and immunity. J Nutr 2003; 133: Suppl. 1, 336S-340S.

9 Willig TN, Paulus J, Lacau Saint Guily J, Beon C, Navarro J. Swallowing problems in neuromuscular disorders. Arch Phys Med Rehabil 1994; 75: 1175-1181.

10 Niederman MS, Merrill WW, Ferranti RD, Pagano KM, Palmer LB, Reynolds HY. Nutritional status and bacterial binding in the lower respiratory tract in patients with chronic tracheostomy. Ann Intern Med 1984; 100: 795-800.

11 Goldstein M, Meyer S, Freund HR. Effects of overfeeding in children with muscle dystrophies. JPEN J Parenter Enteral Nutr 1989; 13: 603-607.

12 Okada K, Manabe S, Sakamoto S, Ohnaka M, Niiyama Y. Protein and energy metabolism in patients with progressive muscular dystrophy. J Nutr Sci Vitaminol (Tokyo) 1992; 38: 141-154.

13 Willig TN, Bach JR, Venance V, Navarro J. Nutritional rehabilitation in neuromuscular disorders. Semin Neurol 1995; 15: 18-23.

14 Aldrich TK. Nutritional factors in the pathogenesis and therapy of respiratory insufficiency in neuromuscular diseases. Monaldi Arch Chest Dis 1993; 48: 327-330.

15 Matsumura T, Saito T, Miyai I, Nozaki S, Kang J. Excess caloric intake induced severe hypercapnia in a patient with Duchenne muscular dystrophy on noninvansive positive pressure ventilation. Rinsho Shinkeigaku 1998; 38: 822-825.

16 Edmonds CJ, Smith T, Griffiths RD, Mackenzie J, Edwards RH. Total body potassium and water, and 
exchangeable sodium, in muscular dystrophy. Clin Sci (Lond) 1985; 68: 379-385.

17 Ben-Porat M, Sideman S, Bursztein S. Energy metabolism rate equation for fasting and postabsorptive subjects. Am J Physiol 1983; 244: R764-R769.

18 Melchior JC, Raguin G, Boulier A, et al. Resting energy expenditure in human immunodeficiency virus-infected patients: comparison between patients with and without secondary infections. Am J Clin Nutr 1993; 57: 614-619.

19 Feinberg M, Ireland-Ripert J, Favier JC. Validated data banks on food composition: concepts for modeling information. World Rev Nutr Diet 1992; 68: 49-93.

20 Harris W, Benedict F. A biometric study of basal metabolism in man. Carnegie Institution 1919; 40-44.

21 Creutzberg EC, Schols AM, Bothmer-Quaedvlieg FC, Wouters EF. Prevalence of an elevated resting energy expenditure in patients with chronic obstructive pulmonary disease in relation to body composition and lung function. Eur J Clin Nutr 1998; 52: 396-401.

22 Ravussin E, Swinburn BA. Pathophysiology of obesity. Lancet 1992; 340: 404-408.

23 Roza AM, Shizgal HM. The Harris Benedict equation reevaluated: resting energy requirements and the body cell mass. Am J Clin Nutr 1984; 40: 168-182.

24 Jozefowicz RF, Welle SL, Nair KS, Kingston WJ, Griggs RC. Basal metabolic rate in myotonic dystrophy: evidence against hypometabolism. Neurology 1987; 37: 1021-1025.

25 Westerterp KR, Wouters L, van Marken Lichtenbelt WD. The Maastricht protocol for the measurement of body composition and energy expenditure with labeled water. Obes Res 1995; 3: 49-57.

26 McCrory MA, Kim HR, Wright NC, Lovelady CA, Aitkens S, Kilmer DD. Energy expenditure, physical activity, and body composition of ambulatory adults with hereditary neuromuscular disease. Am J Clin Nutr 1998; 67: 1162-1169.

27 Hankard R, Gottrand F, Turck D, Carpentier A, Romon M, Farriaux JP. Resting energy expenditure and energy substrate utilization in children with Duchenne muscular dystrophy. Pediatr Res 1996; 40: 29-33.

28 Zanardi MC, Tagliabue A, Orcesi S, Berardinelli A, Uggetti C, Pichiecchio A. Body composition and energy expenditure in Duchenne muscular dystrophy. Eur J Clin Nutr 2003; 57: 273-278.

29 Zurlo F, Larson K, Bogardus C, Ravussin E. Skeletal muscle metabolism is a major determinant of resting energy expenditure. J Clin Invest 1990; 86: 1423-1427.

30 Kayser C. Dépense d'énergie et travail musculaire [Energy expenditure and muscle's work]. In: Physiology. Vol. 3. Paris, Editions Médicales Flammarion, 1963; pp. 9193.

31 Roussos C, Zakynthinos S. Respiratory muscles energetics. 2nd Edn. New York, Marcel Dekker, 1995; pp. 681-749.

32 Edwards RH, Round JM, Jackson MJ, Griffiths RD, Lilburn MF. Weight reduction in boys with muscular dystrophy. Dev Med Child Neurol 1984; 26: 384-390.

33 Tanner JM, Whitehouse RH, Takaishi M. Standards from birth to maturity for height, weight, height velocity, and weight velocity: British children, 1965. II. Arch Dis Child 1966; 41: 613-635.

34 Tanner JM, Whitehouse RH, Takaishi M. Standards from birth to maturity for height, weight, height velocity, and weight velocity: British children, 1965. I. Arch Dis Child 1966; 41: 454-471.

35 Edmonds CJ, Smith T, Griffiths RD, Mackenzie J, Edwards RH. Total body potassium and water, and exchangeable sodium, in muscular dystrophy. Clin Sci (Lond) 1985; 68: 379-385. 